\title{
Protective effects of pre-germinated brown rice extract against amyloid $\beta$-peptide induced neurotoxicity in neuronal SK-N-SH cells
}

\author{
Rungtip Soi-ampornkul ${ }^{1,}$, , Chatchawan Srisawat ${ }^{1}$, Wipawan Thangnipon ${ }^{3}$, Surin Kanyok ${ }^{1}$, \\ Sarawut Junnu', Wanphen Katanyoo ${ }^{1}$, Sompong Liammongkolkul ${ }^{1}$, Pairat Soi-ampornkul ${ }^{2}$ \\ ${ }^{1}$ Department of Biochemistry, Faculty of Medicine Siriraj Hospital, Mahidol University, Bangkok,Thailand \\ ${ }^{2}$ Surasak montree school, The Ministry of Education, Wipawadee road, Huaikhwang, Bangkok, Thailand \\ ${ }^{3}$ Research Center for Neuroscience, Institute of Molecular Biosciences, Mahidol University, Salaya, Nakhonpathom, Thailand
}

\section{Email address:}

rungtip-soi@mahidol.ac.th(R. Soi-ampornkul)

\section{To cite this article:}

Rungtip Soi-ampornkul, Chatchawan Srisawat, Wipawan Thangnipon, Surin Kanyok, Sarawut Junnu, Wanphen Katanyoo, Sompong Liammongkolkul, Pairat Soi-ampornkul. Protective Effects of Pre-Germinated Brown Rice Extract against Amyloid $\beta$-Peptide Induced Neurotoxicity in Neuronal SK-N-SH Cells. International Journal of Nutrition and Food Sciences. Vol. 2, No. 4, 2013, pp. 167-173. doi: $10.11648 /$ j.ijnfs.20130204.12

\begin{abstract}
Amyloid $\beta$-peptide $\left(\mathrm{A} \beta_{1-42}\right)$ is the major component of amyloid plaques and is believed to induce oxidative stress and inflammation in brain, which are postulated to play important roles in the pathogenesis of Alzheimer's disease (AD). The present study investigated the effect of pre-germinated brown rice extract (Oryza sativa L., PGBR ex) which contains a much higher concentration of essential amino acids, such as lysine, isoleucine, methionine and several kinds of antioxidants than conventional brown rice, and over 8-13 times the amount of $\gamma$-aminobutyric acid (GABA) shown to protect against oxidative stress and cell death. Pre-treatment of SK-N-SH cells with $2000 \mu \mathrm{g} / \mathrm{ml}$ PGBR ex significantly attenuated $10 \mu \mathrm{M} \mathrm{A} \beta_{1-42}$-induced neuronal cells deaths. Apoptotic cells death was demonstrated morphologically as well as by detection of the presence of activated caspase-3, DNA fragmentation and the production of reactive oxygen species (ROS) which could be reduced by pre-treatment of PGBR ex and brown rice extract (BR ex). These results suggest that the protective effect of PGBR ex and $B R$ ex against $A \beta_{1-42}$-induced neuronal cell death might be due to its anti-oxidative and anti-apoptotic properties and could be useful as a value added functional food to prevent neurodegenerative diseases.
\end{abstract}

Keywords: Brown Rice Extract, SK-N-SH Cells, Antioxidant, GABA, ROS, A $\beta_{1-42}$, Apoptosis, DNA Fragmentation

\section{Introduction}

Alzheimer's disease (AD) is a progressive neurodegenerative disorder. Amyloid $\beta$-peptide $\left(\mathrm{A} \beta_{1-42}\right)$ is the major component of amyloid plaques and is considered to have a causal role which initiator of a pathological cascade that leads to oxidative stress and neuronal dysfunction. A 1-42 was shown to have the potential to induce oxidative stress and inflammation in the brain, which are postulated to play important roles in the pathogenesis of Alzheimer's disease [1,2]. For example, A $1-42$ induces the production of hydrogen peroxide and lipid peroxide in neurons [3]. In addition, A ${ }_{1-42}$ has been reported to induce superoxide [4] and proinflammatory cytokines $[5,6]$ in astrocytes as well as in microglial cells. Antioxidants such as-tocopherol protect against cytotoxicity in vitro [7] as well as learning and memory deficits induced by A . Furthermore, -tocopherol and antiinflammatory agents such as indomethacin reportedly slow the progression of Alzheimer's disease [9].

Rice is a major cereal food and a dietary staple worldwide, especially in Asian countries. Rice seeds and rice germ contain fiber and several kinds of antioxidants, such as ferulic acid, phytic acid, tocopherols, and oryzanols [10]. Brown rice (BR) is a rice seed form which only the hull is removed. Recently, we found that pre-germinated brown rice (PGBR) contains a much higher concentration of essential amino acids, such as lysine,isoleucine, methionine, than conventional brown rice, and over 13 times the amount of - aminobutyric acid (GABA) [11, 12]. PGBR is brown rice, which has been soaked in water for up to a day and had a germ of approximately $1 \mathrm{~mm}$ long. 
During germination, nutrients in the brown rice change drastically. Nutrients that increase in content include GABA, dietary fiber, inositols, ferulic acid, phyticacid, tocotrienols, magnesium, potassium, zinc, $\gamma$-oryzanol, and prolyendopeptidase inhibitor. According to previous studies they reported that germinated brown rice contained more total ferulic acid (126\%), total dietary fiber (145\%), soluble dietary fiber (120\%) and insoluble dietary fiber (150\%) compared to the brown rice [13]. The neuroprotective activity of various natural extractshas been reported in the literature [14]. Ferulic acid (4-hydroxy-3-methoxycinnamic acid), a phenolic compound present in a variety of plants, has potentantioxidant and anti-inflammatory activities [15]. Among them rice bran is a by-product of the rice milling process and contains various antioxidant factors showing beneficial effects on human health. As well known antioxidants in rice bran, tocopherols, tocotrienols, oryzanols (ferulate esters of triterpene alcohols) are isolated from fat-soluble extracts of rice bran and they have potent hypocholesterolemic and antitumor properties. However, to date, no attempts have been made to investigate the effects of brown rice extracts containing high levels of GABA on proliferation and apoptosis of neuronal cells. The antioxidants of the water-soluble extract of rice bran have been poorly analyzed. Therefore, we hypothesized that the PGBR ex enhanced GABA level may have beneficial effect against $A \beta_{1-42}$-induced neurotoxicity and apoptosis on SK$\mathrm{N}-\mathrm{SH}$ cells. To address this hypothesis, we investigated various methods to study by MTT assay, DNA fragmentation, Caspase-3 activity and ROS formation. The significance of this finding is discussed from the viewpoint of the preventive role of the rice bran against $A \beta_{1-42}$ related chronic diseases.

\section{Materials and Methods}

\subsection{Cells Culture}

The human neuroblastoma SK-N-SH cells line was obtained from the ATCC (Rockville, MD, USA) and maintained in minimum essential medium (MEM) (Life Technology, Inc.) containing $2 \mathrm{mM}$ L-glutamine in a humidified incubator at $37{ }^{\circ} \mathrm{C}$ and $5 \% \mathrm{CO}_{2}$. The medium was supplemented with $10 \%$ fetal bovine serum, $1 \mathrm{mM}$ sodium pyruvate, $0.1 \mathrm{mM}$ nonessential amino acids (Life Technology, Inc.), 100 units $/ \mathrm{ml}$ penicillin, and $100 \mathrm{mg} / \mathrm{ml}$ streptomycin (Biofluids, Rockville, MD). Cells were maintained for $24 \mathrm{~h}$ before treatments.

Cultures were plated at $1 \times 10^{5}$ cells $/ \mathrm{ml}$ in 96 well plates for ROS assay, cells viability (MTT assay), and $1 \times 10^{6}$ cells/ml in 6 well plates for genomic DNA extraction using the Apoptotic DNA Kit, (Roche Applied Science, Mannheim, Germany) and caspase-3 activity assay using $\mathrm{CaspACE}^{\mathrm{TM}}$ assay kit (Promega; San Luis Obispo, CA).

\subsection{Preparation of Rice Extracts}

PGBR (Oryza sativa L.) was supplied by Innofood
(Thailand) Co., Ltd. PGBR was germinated by soaking in the following solutions at $25-26^{\circ} \mathrm{C}$ kept in the dark for $72 \mathrm{~h}$ : was air dried and frozen in liquid nitrogen. Rice extracts were prepared as previously described [16]. Briefly, PGBR, brown rice (BR) and white rice (WR) was ground with a grinder, The milling rice were weight $0.1 \mathrm{~g}$ in $1 \mathrm{~mL}$ of distilled water mix with Vortex for 10 min follow incubated in water bath at $70^{\circ} \mathrm{C}$ for $30 \mathrm{~min}$. then centrifuged at 10,000 $\mathrm{rpm}$ at $4^{\circ} \mathrm{C}$ for $30 \mathrm{~min}$. The supernatants were collected by passed through the filters (pore size $0.45 \mu \mathrm{m}$ ) kept at $-20^{\circ} \mathrm{C}$ and used as rice extracts (rice ex).

\subsection{Determination of $G A B A$ Levels}

GABA levels were quantified by high-performance liquid chromatography (2695 Seperations Module, Waters Corporation, USA) with photodiode array detector (Waters 2996). Samples were separated on a Supelco LC-DABS HPLC column $(4.6 \mathrm{~mm} \times 150 \mathrm{~mm}$ in length and $3 \mu \mathrm{m}$ beads). The milling rice was weight $0.5 \mathrm{~g}$ in plastic tube and added with deionized water $2 \mathrm{~mL}$. The sample solution was fully mix, then centrifuged at $4500 \mathrm{rpm}$ for $10 \mathrm{~min}$. Supernatant was pipette $1 \mathrm{~mL}$ then added with $200 \mu \mathrm{L}$ of $0.4 \mathrm{M} / \mathrm{L} \mathrm{NaHCO}_{3}$ and $400 \mu \mathrm{L}$ of $6 \mathrm{mM} / \mathrm{L}$ DABSYL-Cl acetonitrite solution. The reaction was performed at $70^{\circ} \mathrm{C}$ for $20 \mathrm{~min}$. After derivertization, the sample was filtered to vial and $10 \mu \mathrm{L}$ of sample was injected into HPLC [17].

\subsection{Effect of Rice Extracts on Viabilities of SK-N-SH Cells}

To study the cytotoxicity of rice ex on cell viability which induced by $A \beta_{1-42}$. Cells were plated in 96 well plates. Rice ex were pre-treated with increasing concentrations $(0$ $4000 \mu \mathrm{g} / \mathrm{ml})$ at $37^{\circ} \mathrm{C}$ for $24 \mathrm{~h}$ or treated with $A \beta_{1-42}$ alone to determine for time and concentrations dependent manner. In addition to study the protective effects of rice ex by pretreatment $2000 \mu \mathrm{g} / \mathrm{ml}$ for $3 \mathrm{~h}$ then added with $\mathrm{A} \beta_{1-42}$ and incubated for $24 \mathrm{~h}$. The cells viabilities were assessed by the MTT [3-(4,5-dimethylthiazol-2-yl)2,5diphenyltetra zolium-bromide] assay [18], MTT solution was added at a final concentration of $0.5 \mathrm{mg} / \mathrm{ml}$ and incubation for $3 \mathrm{~h}$. The supernatant was removed and solubilize solution (DMSO) was added, the plates were shaken for $10 \mathrm{~min}$ and absorbance was read at $570 \mathrm{~nm}$ using a microplate reader (Synergy HT, BioTek Instrument).

\subsection{Antioxidant Activity Test}

\subsubsection{Effect of Rice Extracts on Apoptosis by DNA Fragmentation}

Rice ex were pre-treated into the cultures at $2000 \mu \mathrm{g} / \mathrm{mL}$ and incubated at $37^{\circ} \mathrm{C}$ for $3 \mathrm{~h}$ then added with $\mathrm{A} \beta_{1-42}$ for 24 h. Cells were collected. Genomic DNA was extracted using the Apoptotic DNA Ladder Kit,) with slightly modification. In brief, cells were washed twice with ice cold 1x PBS, then $200 \mu \mathrm{L}$ of lysis buffer was added and mixed immediately. After incubated at $22^{\circ} \mathrm{C}$ for $10 \mathrm{~min}, 100 \mu \mathrm{L}$ of $100 \%$ isopropanol was added and vortex for $10 \mathrm{sec}$. The 
lysate was run through the column and washed twice with washing buffer. DNA was eluted with $200 \mu \mathrm{L}$ of prewarmed $\left(70^{\circ} \mathrm{C}\right)$ elution buffer and concentrated by a speedvac. Extracted DNA was subjected to gel electrophoresis, and the image was captured with GelDoc ${ }^{\mathrm{Tm}}$ EQ (Bio-Rad Laboratories, Ltd. Hercules, CA).

\subsubsection{Effect of Rice Extracts on Apoptosis by CASPASe-3 Activity Assay}

Caspase-3 activity assay was determined using a colorimetric assay kit, CaspACE ${ }^{\mathrm{TM}}$ assay system, according to the manufacturer's instructions. Rice ex were pre-treated to the cultures $2000 \mu \mathrm{g} / \mathrm{mL}$ and incubated at $37^{\circ} \mathrm{C}$ for $3 \mathrm{~h}$ then added with $A \beta_{1-42}$ for $24 \mathrm{~h}$. Culture was lysate and 100 $\mu \mathrm{g} /$ well of total lysate protein were used. The specific cleavage of substrate DEVD-pNA by caspase-3 activity was measured at wavelength $405 \mathrm{~nm}$. The results were expressed as the ratio comparing to the untreated control.

\subsection{Antioxidant Activity Test}

To detection of intracellular ROS, the production of ROS was estimated by using a fluorescent probe, 2', 7'dichlorofluoresceindiacetate (DCFH-DA) [19]. DCFH-DA was transported across the cell membrane and hydrolyzed by intracellular esterase to form non-fluorescent 2', 7'dichloro-fluorescein (DCFH), which is then rapidlyconverted to highly fluorescent 2', 7'dichlorofluorescein (DCF) in the presence of ROS. The DCF fluorescence intensity is believed to be parallel to the amount of ROS formed intracellular. To determine the amounts of ROS induced by $\mathrm{A} \beta_{1-42}$, DCFH-DA (50 M final concentration) were added to the culture for $45 \mathrm{~min}$ and then rice ex $(2000 \mathrm{~g} / \mathrm{ml})$ for $30 \mathrm{~min}$ before added with $A \beta_{1-42}$ and incubation at $37^{\circ} \mathrm{C}$ for $3 \mathrm{~h}$. The production of ROS was measured by microplate reader (Synergy HT, BioTek Instrument) with excitation and emission wavelength at $485 \mathrm{~nm}$ and $530 \mathrm{~nm}$ respectively.

\subsection{Statistical Analysis}

Results are expressed as the mean $\pm \operatorname{SD}(n=3)$. Data were analyzed by one-way ANOVA, followed by Dunnett's test for comparison between control and treated experimental groups. Differences were considered significant at a $P$ value of $<0.05$.

\section{Results and Discussion}

\subsection{Analysis of GABA from Rice Extracts by HPLC Method.}

PGBR ex with enhanced GABA level were tested comparable with BR ex and WR ex. The content of GABA in the PGBR ex, BR ex and WR ex were compared with standard GABA. The concentration of GABA in PGBR ex $(9.90 \mathrm{mg} \pm 0.02 / 100 \mathrm{~g}$ of flour) was 3 times and 8 times higher than the GABA content in BR ex $(3.30 \pm 0.01$ $\mathrm{mg} / 100 \mathrm{~g}$ of flour) and in WR ex $(1.24 \pm 0.02 \mathrm{mg} / 100 \mathrm{~g}$ of flour) respectively, as shown in Table.1 (the data average are base on three measurement of each sample).

Table 1. The content of GABA from rice extracts

\begin{tabular}{lc}
\hline Type of rice & Content of GABA(mg/100g of flour $)$ \\
\hline PGBR ex & $9.90 \pm 0.02^{\mathrm{a}}$ \\
BR ex & $3.30 \pm 0.01^{\mathrm{a}}$ \\
WR ex & $1.24 \pm 0.02^{\mathrm{a}}$ \\
\hline
\end{tabular}

${ }^{\mathrm{a}}$ Results are given as Mean Values $\pm \mathrm{SD}(\mathrm{n}=3)$

\subsection{The Cytotoxicity of Rice Extracts and A $\beta_{1-42}$ on SK-N- SH Cells}

First, we attempted to establish the cytotoxicity of rice ex by using the doses dependent on human neuronal SK-N-SH cells. PGBR ex, BR ex and WR ex was applied by increasing concentrations $0-4000 \mu \mathrm{g} / \mathrm{ml}$ for $24 \mathrm{~h}$. We found that the number of cells viability had no significantly different to decrease. The cells survival were up to $96.4 \pm$ $0.052 \%(p>0.48)$, PGBR ex $98.9 \pm 0.032 \%(p>0.30)$, BR ex $96.3 \pm 0.039 \%(p>0.39)$, and WR ex $95.3 \pm 0.037 \%$ $(p>0.25)$ respectively. These data showed no toxicity of rice extracts affect on human neuronal SK-N-SH cells (Figure $1)$.

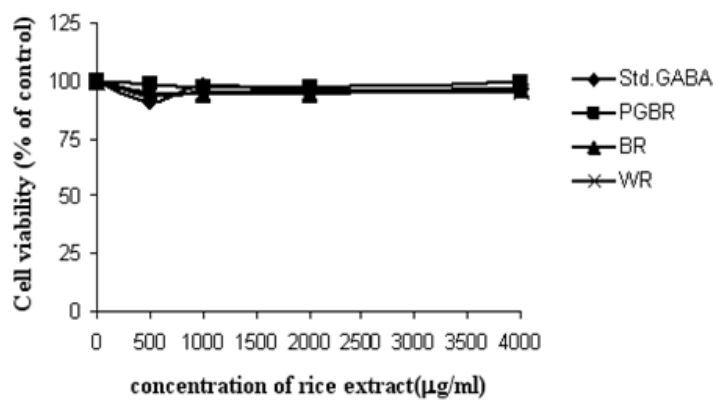

Figure 1. The Effects of rice ex on $S K-N-S H$ cells viability using MTT assay. Pre-incubated cells with increasing concentrations of rice ex at 0 $4000 \mu \mathrm{g} / \mathrm{ml}$. Results are expressed as percentages of the control value $(C O N)$ and data shown are means $\pm S . D$ of three replicate experiments.

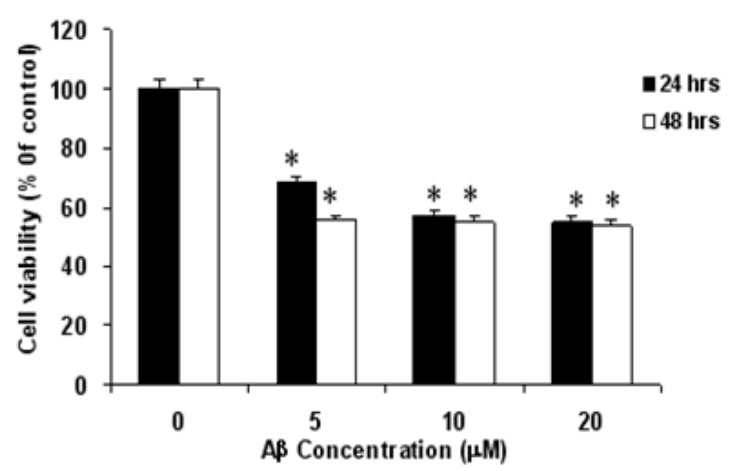

Figure 2. The Effects of $A \beta_{1-42}$ on $S K-N-S H$ cells viability using MTT assay. Cells viability was significantly decreased on time and concentration dependent manner. Results are expressed as percentages of the control value. $*=P<0.05$ compared to the untreated control.

Similar as Chan-Ho Oh and Suk-Heung Oh [16], they tested the effects of the BR ex on the viability of Hela cells, 
by treated cells with the BR ex $2000 \mu \mathrm{g} / \mathrm{ml}$ in cultured and the viability of the cells was assayed. They showed that BR ex had no effects on the retardation of HeLa cell survival and proliferation. To evaluated the cytotoxicity of $A \beta_{1-42}$ by using time and concentrations dependent manner. Cells were treated with $0-20 \mu \mathrm{M}$ of $\mathrm{A} \beta_{1-42}$ for $24 \mathrm{~h}$ and $48 \mathrm{~h}$ The results showed that $A \beta_{1-42}$ caused cells death $57.3 \pm 0.03 \%$ $(p<0.05)$ compared with control. These data indicated that $\mathrm{A} \beta_{1-42}$ was toxicity to SK-N-SH cells depending on time and concentration as shown in Figure 2.

\subsection{Protective Effect of Rice Extracts Inhibit Neuronal Cell Death Induced by $A \beta_{1-42}$}

The protective effects of the rice ex on the viability of SK-N-SH cells were evaluated. The effects of PGBR ex with enhance levels of GABA against $10 \mu \mathrm{M} A \beta_{1-42}$ induced cytotoxicity by compared with BR ex, and WR ex. Cells were pre-treated with the PGBR ex, BR ex and WR ex at $2000 \mu \mathrm{g} /$ well for $3 \mathrm{~h}$ and then added with $A \beta_{1-42}$ for 24 h. These results showed that PGBR and BR extracts can protect cells by significantly increase cell survival up to $30.74 \pm 0.02 \%$ and $21.53 \pm 0.04 \%(p<0.05)$, but not WR ex comparable with $\mathrm{A} \beta_{1-42}$ alone which caused cells death $57.3 \pm 0.03 \% \quad(p<0.05)$, when compared with control as shown in Figure 3. Recently, it has been reported that the long-term administration of ferulic acid acts to protect against $\mathrm{A} \beta_{1-42}$-induced neurotoxicity and memory disturbance.

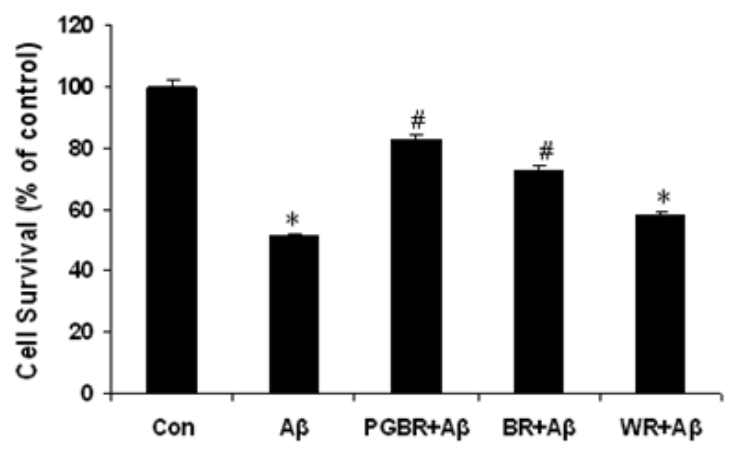

Figure 3. The Protective effects of rice ex on $\mathrm{SK}-\mathrm{N}-\mathrm{SH}$ cells viability induced by $A \beta_{1-42}$ by MTT assay. Pre-treated with rice ex significantly increase cells viability. Results are expressed as percentages of the control value. The data shown are means $\pm S D(n=3) . *=P<0.05$ compared to the untreated control; $\#=P<0.05$ compared to the $A \beta_{1-42}$-treated group, respectively.

\subsection{Effect of Rice Extracts on Apoptosis and DNA Fragmentation of $\mathrm{SK}-\mathrm{N}-\mathrm{SH}$ Cells}

To verify the possible involvement of apoptosis in the $\mathrm{A} \beta_{1-42}$ induced death of neuronal SK-N-SH cells, DNA fragmentation was tested on these cells. We investigated its inhibitory effect on the apoptosis induced by $A \beta_{1-42}$ by observing DNA fragmentation levels in SK-N-SH cells. As a control, we used DNA isolated from untreated cells. Only the degraded DNA was extracted, not the intact chromosomal DNA, from apoptotic and non-apoptotic cells.
Treatment with $\mathrm{A} \beta_{1-42}$ to cells resulted in the characteristic apoptotic DNA ladder (Figure 4). These DNA fragmentation patterns are entirely consistent with the molecular weight patterns expected to result from internucleosomal DNA cleavage (20). DNA fragments smeared the whole lane in the condition of $A \beta_{1-42}$ treated alone and smear band was decrease in the condition of pretreatment with PGBR ex and followed added by $A \beta_{1-42}$. According to administration of PGBR ex alone and nontreated cells (control) did not cause cell death. Similar as the previous studies have shown that intracellular ROS have been implicated with DNA fragmentation and apoptosis [21].

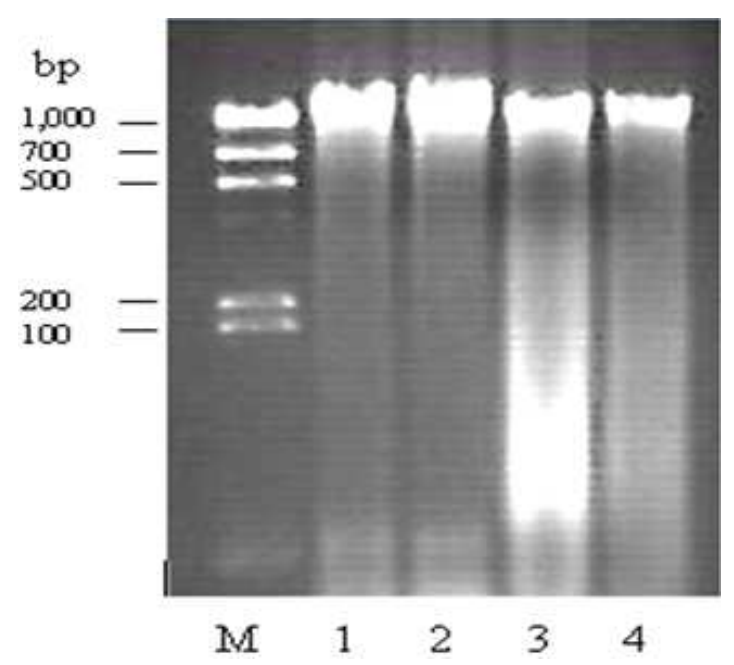

Figure 4. $P G B R$ ex protect $S K-N-S H$ cells against $A \beta_{1-42}$-induced apoptosis examined by DNA fragmentation. Pre-treatment with PGBR ex were reduced DNA fragmentation. Genomic DNA was then extracted and subjected to gel electrophoresis. The image was captured with GelDoc ${ }^{T m}$ EQ (Bio-Rad Laboratories, Ltd. Hercules, CA). Marker; M., control (nontreated-cells);lane 1, PGBR ex; lane 2, $10 \mu M A \beta_{1-42}$;lane 3. PGBR ex and $10 \mu M A \beta_{1-42}$; lane 4 .

\subsection{Effect of Rice Extracts Inhibits Caspase-3 Activity}

Caspase-3 belongs to a family of evolutionally conserved cysteine proteases that play a key role in regulating programmed cell death, or apoptosis, a normal process required for maintenance of tissue homeostasis and the regulation of physiological functions [22] Once caspase-3 is activated, a series of irreversible events are set in motion that lead to the death of the cell, including activation of the CAD endonuclease that degrades DNA within the nucleus and initiates chromatin condensation. Increasing evidence suggests involvement of caspase- 3 in Alzheimer's Disease (AD) via cleavage of amyloid prescursor protein (APP) and tau and the formation of beta-amyloid (A $\beta)$ and neurofibrillary tangles (NFTs), making caspase-3 an interesting therapeutic target [23].The evidence of apoptotic cell death by $\mathrm{A} \beta_{1-42}$ in this study was showed by increased the level of caspase-3 activity compared to untreated controls. According to pre-treatment with $2000 \mu \mathrm{g} / \mathrm{ml}$ of PGBR ex and BR ex significantly inhibited the content of activated caspase-3 (Figure 5). 


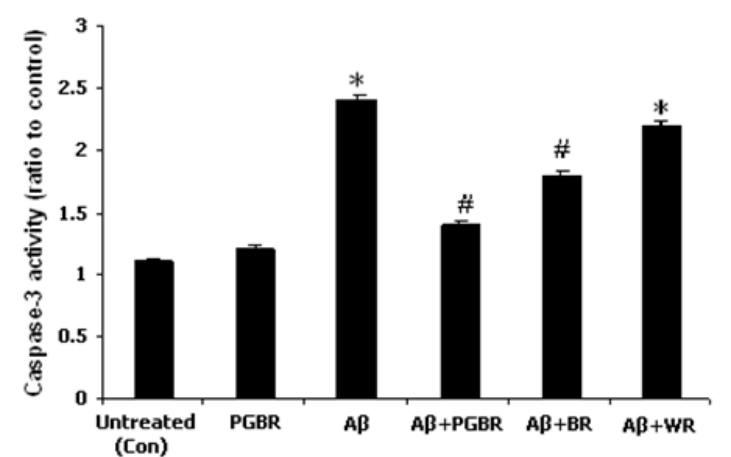

Figure 5. Effects of rice ex induced by $A \beta_{1-42}$, on caspase-3 activity in $S K$ $\mathrm{N}$-SH cells. The caspase- 3 activity was measured at $3 \mathrm{~h}$ after treatment with $10 \mu M A \beta_{1-42}$ in the presence or absence of the $2000 \mu \mathrm{g} / \mathrm{ml}$ of rice ex and represents as the ratio to the caspase activity of the untreated control. The data shown are means $\pm S D(n=3) . *=\mathrm{P}<0.05$ indicated statistically significant differences compared with the untreated control and $\#=$ $\mathrm{P}<0.05$ indicated statistically significant differences compared with the $A \beta_{1-42}$ treated group, respectively.

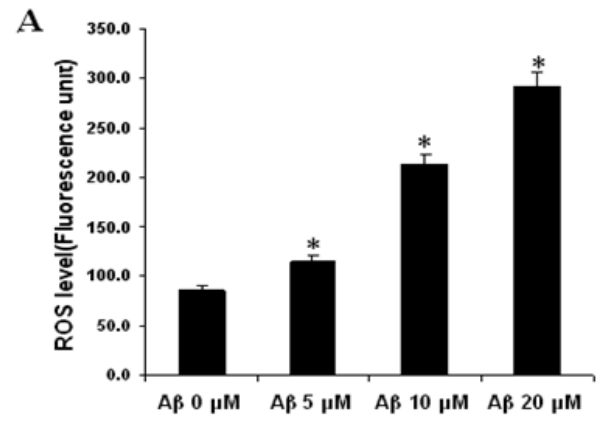

B

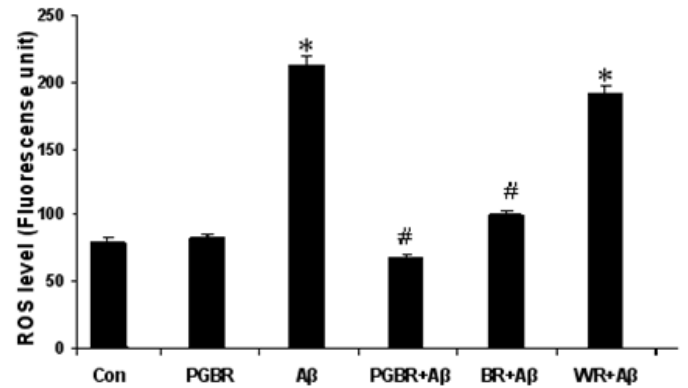

Figure 6. Intracellular ROS generation using the DCFHDA assay, to measure DCF in neuronal SK-N-SH cells. ROS levels were increased by induction with $A \beta_{1-42}$ in a dose dependent manner $(A)$. Intracellular ROS levels are significantly reduced by pre-treatment of $P G B R$ ex and $B R$ ex (B). The data shown are means $\pm S D(n=3) . *=\mathrm{P}<0.05$ compared to the untreated control; $\#=\mathrm{P}<0.05$ compared to the $A \beta_{1-42}$-treated group, respectively.

\subsection{Effect of Rice Extracts Inhibits $A_{\beta_{1-42}}$ Induced ROS Generation}

The intracellular radical scavenging activity of a given substance can be evaluated by DCFHDA assay. To determine whether rice ex inhibits the ROS generation induced by $\mathrm{A} \beta_{1-42}$ in neuronal SK-N-SH cells, and to determine whether the protection of SK-N-SH neuronal cells from apoptosis is accompanied by free radicals scavenging by the rice ex, changes in the concentrations of
ROS in whole cell suspensions were analyzed over a $2 \mathrm{~h}$ period after treatment with PGBR ex and BR ex and/or $A \beta_{1-}$ 42. Non-treated SK-N-SH cells showed relatively low levels of basal fluorescence, while treated with $A \beta_{1-42}$ alone for 3 $\mathrm{h}$, a marked increase inflorescence was observed. However, this increased in fluorescence by $A \beta_{1-42}$ rapidly returned to the control level after pre-treatment with in PGBR ex and BR ex $(2000 \mu \mathrm{g} / \mathrm{ml})$ to the cells as shown in Figure 6 . Similar study had reported that the addition of $A \beta_{1-42}$ to neural cells leads to the rapid production of $\mathrm{H}_{2} \mathrm{O}_{2}$ and lipid peroxidation, suggesting that $A \beta_{1-42}$ toxicity is mediated by free radical damage [24].

\section{Conclusion}

The main objective of present study was to evaluate the protective effects of rice ex to protect neuronal SK-N-SH cells which induced by $A \beta_{1-42}$. By taking into account, these results demonstrated that PGBR ex and BR ex are potent scavengers of free radical. The results showed protective effects by increased cells survival and inhibit the induction of apoptosis by decrease level of DNA fragmentation ladder and caspase-3 activity. Recently, it has been reported that the long-term administration ferulic acid acts to protect against $\mathrm{A} \beta_{1-42}$-induced neurotoxicity and memory disturbance [25]. Previously reports had hypothesized that oxidative stress is one of the mechanisms of $A \beta_{1}$. ${ }_{42}$-inducedneurotoxicity. In vitro studies have shown that $\alpha$-tocopherol, a representative antioxidant, inhibits $A \beta_{1-42}$ induced neuronal cell death and lipid peroxidation [26]. Ferulic acid also possesses free radical scavenging activity and reduces peroxidative damage [27]. Thus, PGBR may ameliorate $A \beta_{25-35}$-induced learning and memory deficits by scavenging oxidative stress.

Very recently, it has been reported that GABA and its receptor agonist improve cognitive decline that accompanies aging in monkeys [28].Taken together, the large amount of GABA in PGBR may regulate the glutamatergic system by enhancing glutamate release and/or the sensitivity of NMDA receptors, resulting in memory enhancement. PGBR ex contains approximately 13 times the amount of GABA than in WR ex. Ferulic acid ester is one of main components of oryzanol, a phytosterol derived from rice bran. Natural antioxidants that can neutralize ROS include cysteine, reduced glutathione, polyphenolic compounds carotenoids, ascorbic acid (vitamin C), $\alpha$-tocopherol (vitamin E) and indolecarbinds. Some researcher have suggested that germination may bring about changes in nutrients and physiologically active substances. During the germination of wheat [29] and Pangium edule Reinw [30], vitamin C, vitamin E, ferulic acid, and total phenolic acid contents increased. Upon malting of finger millet, changes in both free and bound phenolic acid contents were observed and these reflected their antioxidant properties. During the germination of rice seeds, alanine and $\gamma$-aminobutyrate have been reported to increase significantly [31]. We speculatethat, during 
germination, as seed moisture increases, the seed coat has the potential for injury by oxidation and/or microorganism infiltration. Induced saccharolytic enzymes to hydrolyze starch would produce free phenolic compounds having more effective antioxidant activity from hydroxycinnamate sucrose esters. As a result, the content of hydroxycinnamate sucrose esters decreases, whereas that of free phenolic compounds increases. This hypothesis requires verification through further experiments; however, the changes in content and form of phenolic compounds in germinated brown rice suggest that appropriate germination of brown rice may be a method to improve health-related benefits. From previous studies have shown that $\mathrm{A} \beta$ is associated with ROS generation, which leads to mitochondrial dysfunction, lipid peroxidation and apoptosis [5, 17]. Therefore, suppression of ROS generated by antioxidants may be an effective means in preventing oxidative cells death. The present study demonstrated that $A \beta_{1-42}$-induced ROS production and apoptosis of neuronal cultured is attenuated by PGBR ex and BR ex. Thus, PGBR and BR have a potential role in the future in alleviating neuronal apoptotic death associated with neurodegenerative disease.

\section{Acknowledgements}

The authors gratefully acknowledge the financially support from Vejdusit Foundation (Bangkok-Hospital). We really appreciated and wish to thank Department of Biochemistry, Faculty of Medicine Siriraj hospital, Mahidol University.

Conflict of interest: The authors declare no conflict of interest.

\section{References}

[1] Behl, C., 1999. Alzheimer's disease and oxidative stress: implications for novel therapeutic approaches. Prog.Neurobiol. 57, 301-323.

[2] McGeer, P.L., McGeer E.G., 1999. Inflammation of the brain in Alzheimer's disease: implications for therapy. J. Leukoc Biol. 65, 409-415.

[3] Behl, C., Davis, J.B., Lesley, R., Schubert, D., 1994. Hydrogen peroxide mediates amyloid protein toxicity. Cell. 77, 817-827.

[4] McDonald, D.R., Brunden, K.R., Landreth, G.E., 1997. Amyloid fibrils activate tyrosine kinase-dependent signaling and superoxide production in microglia. J. Neurosci.17, 2284-2294.

[5] Araujo, D.M., Cotman, C.W., 1992. -amyloid stimulates glial cells in vitro to produce growth factors that accumulate in senile plaques in Alzheimer's disease. Brain Res.569:141145 .

[6] Gitter, B.D., Cox, L.M., Rydel, R.E., May, P.C., 1995. Amyloid peptide potentiates cytokine secretion by interleukin-1 beta-activated human astrocytoma cells. Proc. Natl. Acad. Sci. USA. 92,10738-10741.
[7] Behl, C., Davis, J., Cole, G.M., Schubert, D., 1992. Vitamin E protects nerve cells from amyloid beta protein toxicity. BiochemBiophys Res. Commun.186, 944-950.

[8] Yamada. K., Tanaka, T., Han, D., Senzaki, K., Kameyama. T., Nabeshima, T., 1999. Protective effects of idebenone and alpha-tocopherol on -amyloid-(1-42)-induced learning and memory deficits in rats: implication of oxidative stress in -amyloid-induced neurotoxicity in vivo. Eur. J. Neurosci. 11, 83-90.

[9] Sano, M., Ernesto, C., Thomas, R.G., Klauber, M.R., Schafer, K., Grundman, M., et al., 1997. A controlled trial of selegiline, alpha-tocopherol, or both as treatment for Alzheimer's disease. The Alzheimer's Disease Cooperative Study. N. Engl. J. Med.336, 1216-1222.

[10] Katyama, M., Yoshimi, N., Yamada, Y., Sakata, K., Kuno, T., Yoshida, K., Qiao, Z., Vihn, P.Q., Iwasaki, T., Kobayash, H., Mori, H., 2002. Preventive effect of fermented brown rice and rice bran against colon carcinogenesis in male F344 rats. Oncology. Rep.9, 817-822.

[11] Oh, S.H., Kim, S.H., Moon, Y.J., Choi, W.G., 2002. Changes in the levels of $\gamma$-aminobutyric acid and some amino acids by application of glutamic acid solution for the germination of brown rices. Korean J. Biotechnol. Bioeng.17, 49-53.

[12] Oh, S.H., 2003. Stimulation of $\gamma$-aminobutyric acid synthesis activity in brown rice by a chitosan/glutamic acid germination solution and calcium/calmodulin. J.Biochem. Mol. Biol.36, 319-325.

[13] Latifah, et.Al., 2010. Germinated brown rice (GBR) reduces the incidence of aberrant crypt foci with the involvement of $\beta$-catenin and COX-2 in azoxymethane-induced colon cancer in rats. Nutrition Journal. 9, 9-16.

[14] Zhang, R., Lu, H., Tian, S., Yin, J., Chen,O., M, L., Cui, S., Niu, Y., 2010. Protective effects of pre-germinated brown rice diet on low levels of $\mathrm{Pb}$-induced learning and memory deficits in developing rat.Chemico-Biological Interactions.184, 484-491.

[15] Okai, K.H., Kanbara, K., Amano, k., Hagiwara, A., Sugita, C., Matsumoto, N.,Okai, Y., 2004. Potent Antioxidative and Antigenotoxic Activity in Aqueous Extract of Japanese Rice Bran - Association with Peroxidase Activity. Phytother Res.18, 628-633.

[16] Oh, C.H., Oh, S.H., 2004. Effects of Germinated Brown Rice Extracts with Enhanced Levels of GABA on Cancer Cell Proliferation and Apoptosis. J. Med. Food.7, 19-23.

[17] Cohen, S.A., Michaud, D.P., 1993. Synthesis of fluorescent derivertizating reagent, 6-Aminoquinolyl-Nhydroxysuccinimidyl carbamate and its application for the analysis of hydrolysate amino acids via high performance liquid chromatography. Anal. Biochem. 211, 279-287.

[18] Soiampornkul, R., Junnu, S., Kanyok, S., Liammongkolkul, S., Katanyoo, W., Umpornsiriratm, S., 2012.Antioxidative and Neuroprotective activities of the Pre-Germinated Brown Rice extract. Food and Nutrition Science.3, 135-140.

[19] Wang, H., Joseph, J.A., 1999. Quantifying Cellular Oxidative Stress by Dichlorofluorescein Assay Using Microplate Reader. Free Radical Biology \& Medicine.27, 612-616.

[20] Bicknell, G.R., Snowden, R.T., Cohen, G.M., 1994. 
Formation of high molecular mass DNA fragments is a marker of apoptosis in the human leukemic cell line, U937. Journal of Cell Science.107, 2483-2489.

[21] Coyle, J.T., Puttfarcken, P., 1993.Oxidative stress. Science.262, 689-695.

[22] Degterev, A., Boyce, M., Yuan, J., 2003. A decade of caspases. Oncogene. 22, 8543-8567.

[23] Elmore, S., 2007. Apoptosis: A Review of Programmed Cell Death.ToxicolPathol. 35, 495-516.

[24] Hockenbery, D.M., Oltvai, Z.N., Yin, X.M., Milliman, C.L., Korsmeyer, S.J., 1993. Bcl-2 functions in an antioxidant pathway to prevent apoptosis. Cell. 75, 241-251.

[25] Yan, J.J., Cho, J.Y., Kim, H.S., Kim, K.L., Jung, J.S., Huh, S.O., Suh, H.W., Kim, Y.H., Song, D.K., 2001. Protection against -amyloid peptide toxicity in vivo with long-term administration of ferulic acid. Br. J.Pharmacol. 133,89-96.

[26] Schubert, D., Behl, C, Lesley, R., Brack, A.,Dargusch, R., Sagara, Y., Kimura, H.,1995 Amyloid peptides are toxic via a common oxidative mechanism. Proc. Natl. Acad. Sci. USA.92, 1989-93.

[27] Scott, B.C., Aruoma, O.I., Evans, P.J., et al., 1994.Lipoic and dihydrolipoic acids as antioxidants. A critical evaluation. Free Radic. Res.20, 119-133.

[28] Leventhal, A.G., Wang, Y., Pu, M., Zhou, Y., Ma, Y., 2003.GABA and its agonists improved visual cortical function in senescent monkeys. Science. 300:812-5.

[29] Yang, F., Basu, T.K.,Ooraikul, B., 2001. Studies on Germination Conditions and Antioxidant Contents of Wheat Grain.Int. J. Food. Sci. Nut.52, 319-330.

[30] Andarwulan, N., Fardiaz, D., Wattimena, G.A.,Shetty, K., 1999. Antioxidant Activity Associated with Lipid and Phenolic Mobilization during Seed Germination of Pangium edule Reinw.J. Agric. Food Chem. 47, 3158-3163.

[31] Tian, S., Nakamura, K.,Kayahara, H., 2004. Analysis of Phenolic Compounds in White Rice, Brown Rice, and Germinated Brown Rice. J. Agric.Food Chem.52, 48084813. 